\title{
Provisioning patterns in the cooperatively-breeding acorn woodpecker: does feeding behaviour serve as a signal?
}

\author{
Walter D. Koeniga,b,*, Eric L. Walters ${ }^{a, c}$ \\ a Cornell Lab of Ornithology, Ithaca, NY 14850 \\ b Department of Neurobiology and Behavior, Cornell University, Ithaca, NY 14853 \\ ${ }^{c}$ Department of Biological Sciences, Old Dominion University, Norfolk, VA 23529
}

Running head: Provisioning patterns in acorn woodpeckers

Address correspondence to W. Koenig, E-mail: wdk4@cornell.edu 
1 Acorn woodpeckers, Melanerpes formicivorus, are cooperative breeders in which social

2 groups consist of both nonbreeding helpers at the nest (offspring from prior reproductive

3 attempts) and cobreeders of one or both sexes (usually siblings or a parent and his/her

4 offspring). Regardless of composition, groups generally have one nest at a time at

5 which all individuals participate in provisioning offspring. We tested the hypothesis that

6 provisioning behaviour serves a signalling function used to gain social advantages

7 within groups by enhancing dominance, social prestige, or by reducing the likelihood of

8 being expelled from the group ('pay-to-stay'). We found that birds adjusted their

9 provisioning behaviour based on the activities of other group members by clumping their

10 visits and by alternating their visits with other group members, thus synchronising and

11 coordinating provisioning within groups. Despite this evidence that acorn woodpeckers

12 respond to the provisioning behaviour of other group members, analyses of feeding

13 rates and patterns of overlap revealed no support for the hypothesis that provisioning

14 functions as a signal to other group members in any of three ways: breeder males

15 signalling to breeder females to enhance their probability of mating; helpers signalling to

16 other helpers to enhance their dominance or social prestige; or helpers signalling to

17 breeders to reduce the probability that they will be considered 'lazy' and be evicted from

18 the group. Our results add to prior studies that have thus far failed to support a

19 signalling function for provisioning behaviour in avian cooperative breeders.

21 Keywords:

22 cooperative breeding

23 pay-to-stay 
24 provisioning behaviour

25 signalling

26 social prestige

27 
Provisioning of nestlings is a key behaviour of altricial birds, consuming a large

29 fraction of the time and energy budgets of provisioners and having a correspondingly

30 critical effect on parental fitness (Saether, 1994). It is consequently unsurprising that

31 provisioners pay close attention to the needs of nestlings, as evidenced both by their

32 response to nestling begging signals (Kilner \& Johnstone, 1997; Leonard \& Horn, 2001)

33 and their response to changes in the feeding rate of other caregivers (Johnstone \&

34 Hinde, 2006; Hinde \& Kilner, 2007; Harrison, Barta, Cuthill, \& Székely, 2009). The latter

35 is particularly important and complex in cooperative breeders, where nestlings are fed

36 by multiple individuals whose fitness benefits and thus optimal patterns of investment in

37 the brood often differ considerably (Hatchwell, 1999; Raihani, Nelson-Flower, Moyes,

38 Browning, \& Ridley, 2010; Koenig \& Walters, 2012)

39 Despite apparently focusing on different aspects of nesting, however, the

40 response of caregivers to both nesting begging signals and to feeding behaviour of

41 other caregivers often comes down to the question of how provisioners respond to

42 nestling need, the difference being that the former addresses this issue directly while

43 the latter addresses it indirectly. That is, studies investigating changes in feeding

44 behaviour when provisioning activities of caregivers is altered is typically interpreted as

45 being due to concomitant changes in nestling need. When an individual reduces its

46 feeding rate, it results in increased nestling need and compensatory feeding by other

47 group members; conversely, increases in feeding rate by an individual leads to

48 decreased nestling need and 'load-lightening' or reduced provisioning by other group

49 members (Hatchwell, 1999; Canestrari, Marcos, \& Baglione, 2007; Meade, Nam,

50 Beckerman, \& Hatchwell, 2010; Koenig \& Walters, 2012). In contrast, there have been 
51 relatively fewer studies investigating how or if caregivers respond to the feeding

52 behaviour of other provisioners independent of their effect on nestling need (Liebl,

53 Browning, \& Russell, 2016).

$54 \quad$ Why, however, should caregivers be influenced by other provisioners? Two

55 possibilities proposed in the context of group living include the 'social prestige'

56 hypothesis (Zahavi, 1977, 1990, 1995), which proposes that individuals are able to

57 enhance their dominance or social standing within the group by means of their

58 provisioning behaviour, and the 'pay-to-stay' hypothesis, which proposes that increased

59 provisioning by subordinates reduces the likelihood of dominant birds expelling them

60 from the group (Gaston, 1978; Kokko, Johnstone, \& Wright, 2002; Wright \& McDonald, 61 2016).

62 Here we test these two hypotheses, focusing on provisioning behaviour in the

63 cooperatively breeding acorn woodpecker, Melanerpes formicivorus, a species with

64 both a complex polygynandrous mating system and nonbreeding helpers at the nest

65 (Koenig, Walters, \& Haydock, 2016). The general question we address is: do birds alter

66 their behaviour in response to other group members when provisioning nestlings, and if

67 so, is it in a way that indicates they are either attempting to gain some social advantage

68 or otherwise exhibiting their behaviour to other group members so as to decrease the

69 likelihood of dominant birds expelling them from the group? Both these possibilities

70 assume that provisioning behaviour serves a signalling function, which has been

71 supported in at least one social species (the sociable weaver, Philetairus socius;

72 Doutrelant \& Covas, 2007), although not in others (McDonald, Kazem, Clarke, \& Wright, 
73 2008; Nomano, Browning, Rollins, et al., 2013; Nomano, Browning, Savage, et al.,

74 2015; Wright \& McDonald, 2016).

75 We first looked for evidence that birds adjusted their provisioning behaviour

76 based on nest visits by other group members. To do so, we considered several

77 dimensions of such adjustment (Figure 1). Non-randomness in provisioning behaviour

78 along at least one of the three dimensions would indicate that birds are responding to

79 the provisioning behaviour of other individuals in the group, a finding that is necessary

80 in order to demonstrate that provisioning may be used by birds to enhance their social

81 prestige or reduce their probability of being evicted from the group.

82 Sensitivity to the provisioning behaviour of other group members is not, however,

83 sufficient to demonstrate that such behaviour is being used to enhance social prestige.

84 In order to unambiguously test whether provisioning serves a signalling function, we

85 conducted two additional sets of analyses. First we compared the feeding rates of birds

86 as a function of whether they were or were not potentially in competition with other birds

87 of the same sex and status in the group. The prediction of these tests is that if birds are

88 trying to increase their status or prestige by advertising their quality with their

89 provisioning behaviour, they should feed more frequently when they are in groups

90 containing other birds of the same sex and status than when they are not.

91 Second, we quantified the extent that provisioning visits by different individuals

92 overlapped in time more than expected by chance. There are at least three reasons why

93 such behaviour might be advantageous. First, helpers might be attempting to advertise

94 their provisioning to breeders so as to reduce the probability that the latter will expel

95 them from the group; this is the 'pay-to-stay' hypothesis. Second, breeder males might 
96 be advertising their quality to breeder females, in this case by increasing their effort as

97 perceived by breeder females, thereby potentially enhancing the probability of siring

98 young in subsequent breeding attempts. Third, helpers might be advertising their quality

99 to other same-sex helpers, thus increasing their dominance and potentially gaining

100 advantages later when they potentially become cobreeders. All three of these

101 possibilities assume a social prestige function for provisioning behaviour in which birds

102 are advertising their quality or propensity to cooperate for some future reproductive 103 advantage.

104 The 'pay-to-stay' hypothesis has been tested previously in the cooperatively 105 breeding bell miner, Manorina melanophrys, where experimental removal of breeders

106 failed to alter the provisioning behaviour of helpers, thus failing to support the 107 hypothesis that feeding behaviour by helpers serves as a signal to gain social

108 advantage within groups (McDonald et al., 2008). In the acorn woodpecker, helpers that

109 fed more were indeed likely to remain helpers longer and were more likely to inherit

110 their natal territory than broodmates that fed less, predictions consistent with pay-to-stay

111 (Koenig \& Walters, 2011). This result, however, appeared to be a consequence of

112 differences in dispersal behaviour rather than prior feeding history.

113 Several other attempts have failed to identify pay-to-stay in cooperative breeders

114 (Mitchell, 2003; McDonald et al., 2008; Santema \& Clutton-Brock, 2012; Hatchwell,

115 2016), but there is strong evidence for this mechanism playing a role in driving helping

116 behaviour in the cooperatively breeding cichlid fish, Neolamprologus pulcher (Taborsky,

117 2016) and experimental evidence that has been interpreted as supporting this 
118 mechanism in the superb fairy-wren, Malurus cyaneus (Mulder \& Langmore, 1993).

119 Thus, additional examination of this hypothesis is clearly warranted.

\section{Methods}

123 Study Site and Field Methodology

We studied a marked population of acorn woodpeckers at Hastings Reservation,

126 central coastal California, between 1973 and 2015, during which time the population

127 was monitored continuously (Koenig \& Mumme, 1987). Analyses of feeding rates that

128 did not require more detailed data on the timing of individual feeding visits were based

129 on nest watches conducted between 1979 and 2015. Tests that required information on

130 the timing of visits, including analyses of overlap, clumping, and feeding intervals, were

131 based on nest watches conducted during the years $1990-1998,2001-2002$, and

$1322004-2015$, inclusive. For all watches, observers sat in blinds located away from active

133 nests and recorded the identities of all birds engaged in feeding visits with the aid of a

134 spotting scope (Koenig \& Walters, 2012).

135 Watches varied in length, but were typically $3 \mathrm{~h}$ long. During each feeding visit, 136 bird identity, time at which the bird arrived at the nest, time it entered the nest, and time

137 it left the nest were recorded and later transcribed into a computer file. A small

138 proportion (1.4\%) of feeding visits were made by birds that were not identified; these

139 were included in the analyses when individual identity was not relevant to the analysis.

140 The total dataset for analyses involving the timing of feeding visits included 1,713 
141 watches lasting 4,932 hours at 555 different nests of 88 different social groups of birds

142 and included a total of 56,345 feeding visits. A total of 269 breeder males, 221 breeder

143 females, 298 helper males, and 212 helper females were used in the analyses. For the

144 analysis of feeding rates, we included data from a total of 3,405 nest watches lasting

1459,993 hours at 1,056 different nests.

$146 \quad$ Mean $( \pm$ SD) feeding intervals for individual birds was $12.6 \pm 15.7 \mathrm{~min}(N=$

14749,403 intervals), ranging from $11.1 \pm 14.0 \mathrm{~min}$ for breeder females to $14.5 \pm 18.6 \mathrm{~min}$

148 for helper males. For all four categories of birds, the distribution of feeding intervals

149 followed an exponential decay function, with between $36.4 \%$ and $44.6 \%$ of feeding visit

150 intervals being $<5$ min (Figure 2).

Detecting and Interpreting Patterns of Provisioning Behaviour

154 Provisioning behaviour within groups is potentially adjustable along at least three

155 dimensions: clumping of visits by groups of birds, clumping of visits by individual birds,

156 and the incidence of 'runs' of uninterrupted visits by the same bird. A visualisation of the 157 three dimensions is provided in Figure 1 and summarised in Table 1.

158 We refer to runs of uninterrupted visits more common than expected (Table 1, 159 section A) as 'time-sharing,' since birds are temporally separating sets of feeding bouts.

160 Runs less common than expected (section C) are referred to as 'alternate feeding,'

161 since in this case birds alternate their feeding visits with those of other birds in the group

162 (Johnstone et al., 2014; Bebbington \& Hatchwell, 2016). In either case, birds are

163 coordinating their visits with other group members; this is not the case if the lengths of 
164 runs are random (section B). Feeding visits may be clumped (multiple visits may occur 165 within limited periods of time; columns 1 and 2); if so, we refer to this as feeding bouts 166 that are synchronised. It is also possible that feeding bouts by groups but not individuals 167 are clumped (cells B2 and C2; this possibility does not exist if there is time-sharing), but 168 we consider the converse (individuals but not group visits are clumped) unlikely, and do 169 not consider it further. Potential fitness benefits of synchronised and coordinated

170 feeding visits include lower predation and thus increased survivorship due to reduced

171 activity around the nest, as has been reported in the cooperatively breeding pied

172 babbler, Turdoides bicolor, and long-tailed tit, Aegithalos caudatus (Raihani et al., 2010;

173 Bebbington \& Hatchwell, 2016), and reduced parental conflict over care, as proposed

174 for great tits, Parus major (Johnstone et al., 2014).

175 To test for clumping of visits, we considered individuals and all group members

176 combined; individuals were subdivided into one of four categories (breeder males,

177 breeder females, helper males, and helper females) based on their origin and prior

178 history (Koenig, Mumme, \& Pitelka 1984). For each category of bird, we identified visits

179 occurring at least 5 min after any prior provisioning visit of birds in the same category.

180 We then counted the number of visits by the individual or the group as a whole

181 occurring within the next 5-min interval. For comparison with each such event, we

182 randomly chose a time during the watch and counted the number of feeding visits by the

$183 \operatorname{bird}(\mathrm{s})$ in the target category during the subsequent $5 \mathrm{~min}$. We then caculated the

184 number of visits ( 0 to $\left.3^{+}\right)$as the percent greater or less than expected for each category

185 of bird and tested the differences with $\chi^{2}$ tests. Clumping of visits was demonstrated by

186 fewer values in the ' 0 ' and ' 1 ' category and more in the ' 2 ' and ' $3+$ ' visits within 5 min 
187 intervals. The 5 min criterion used in these analyses was based on the distribution of

188 feeding visit intervals plotted in Figure 2, but is nonetheless arbitrary. Parallel analyses

189 using 10-min intervals did not alter the results, however.

190 To test for uninterrupted runs of visits by the same individual, we first determined

191 the observed frequency of runs that were 1, 2, 3, or 4+ visits in length for individuals

192 within each watch for each of the four categories of birds (breeder males, breeder

193 females, helper males, and helper females). The expected frequency was then

194 determined for each watch by counting the total number of visits during the watch by the

195 target bird and all other birds, randomising their order, and counting the number of runs

196 for the target bird that emerged. Randomisations were performed 100 times and the

197 observed number of runs was then compared to the expected frequency as determined

198 by the mean number of runs of each length counted in the randomisation trials.

199 Differences were tested with $\chi^{2}$ tests.

200 All cases except the scenario in which runs are random and there is no clumping

201 of feeding bouts by either individuals or groups (cell B3) are consistent with the

202 hypothesis that birds are responding to the provisioning behaviour of other individuals in

203 the group and thus that provisioning may serve a signalling function. As mentioned

204 earlier, however, these patterns do not prove that birds are signalling one another. For

205 example, provisioning patterns involving greater clumping than expected, particularly at

206 the level of groups (columns 1 and 2), could emerge as a consequence of birds foraging

207 together at the same temporally variable food patches, or from other advantages of

208 staying together and moving as a group, rather than because they are sensitive to each

209 other's provisioning activities. Patterns that do not involve clumping of visits and that are 
210 more evenly distributed in time than expected by chance (cells A3 and C3) are

211 consistent with cooperation among caregivers resulting in optimising interfeeding

212 intervals and efficient feeding of young, since prior work has found that high feeding

213 rates can reduce the mean retention time of digesta in nestling guts and reduce

214 digestive efficiency (Lepczyk, Caviedes-Vidal, \& Karasov, 1998; Karasov \& Wright,

215 2002; Budden \& Wright, 2007). Such an outcome also potentially emerges from the

216 scenario in which there is no clumping and run length is random (cell B3), although in

217 this case it is an emergent property of individual behaviour and not because birds are

218 altering their behaviour in response to the provisioning behaviour of others in the group.

220 Adjustment of Feeding Rate and Overlap

We tested the hypothesis that birds adjusted their feeding rates so as to 223 advertise their quality by means of linear mixed-effects models in which we included the

224 number of birds in the target category in the group as an independent explanatory factor

225 along with variables identified previously as being important to feeding rates in this

226 population: number of nestlings in the nest at the time of the watch (brood size), number

227 of young surviving to banding age, nestling age (both linear and quadratic terms), total

228 group size, time of day the watch began (Pacific Standard Time), and maximum

229 temperature on the day of the watch based on data from the Hastings Reservation

230 weather station (Koenig \& Walters, 2012). The three-way nested factor of 'bird ID' within

231 'nest' within 'territory' was included as a random factor. 
We performed analyses testing two hypotheses: first, that breeder males

233 increase their feeding rates in the presence of cobreeder males so as to advertise their

234 quality to females, and second, that helpers increase their feeding rate in the presence

235 of other helpers of the same sex in order to enhance their social prestige within same-

236 sex coalitions. Reproductive skew between cobreeder males within nests is high, with

237 the most successful male siring three times as many young as the next most successful

238 male, thus setting the stage for more socially dominant cobreeder males to gain a

239 considerable reproductive (Haydock \& Koenig, 2002). In contrast, joint-nesting females

240 share maternity within nests equally (Haydock \& Koenig, 2003) and thus we did not

241 perform parallel tests with breeder females since we have no evidence that females are

242 able to gain a reproductive advantage over their cobreeders as a result of increased

243 social dominance.

244 We performed two sets of analyses for each of the two hypotheses using mixed-

245 effects models (procedure 'Ime' in library 'nlme'; Pinheiro, Bates, DebRoy, Sarkar, \& R

246 Core Team, 2013). The first set controlled for group composition by including the

247 number of birds in each of the four sex and status categories as explanatory factors;

248 only results for the target category are reported. The second set restricted analyses to

249 groups with a specific composition for birds other than those of the target category. For

250 breeder males, we restricted analysis to groups with a single breeder female and no

251 helpers; for helpers, we restricted analysis to groups with a single breeder of both sexes

252 and no helpers of the opposite sex.

253 For analysis of overlaps, we first determined all cases in which a bird visiting the

254 nest overlapped (within $5 \mathrm{sec}$ ) with a bird already in or at the nest. Once an incidence of 
255 overlap was included, all birds involved in that event were excluded from further

256 consideration, thus reducing pseudoreplication. (When two birds were recorded as

257 being at the nest at the same time, the first bird recorded was assumed to be the bird in

258 the nest and the second was assumed to be the bird arriving at the nest.) Because the

259 analysis of overlaps required precise timing, we restricted tests to nests observed from

2602007 onwards, years in which we transcribed nest watches using a computer program

261 written specifically for this purpose. This limited analysis to 578 watches at 260 nests

262 lasting a total of 1,758 hours, and yielded a total of 5,111 overlap events.

263 To generate expected values, we then chose, for each overlap event, a bird of

264 one of the four sex/status categories to be the 'expected' overlapping individual based

265 on the proportion of visits made during the watch by the four categories of birds,

266 excluding the bird already in the nest. For each category of bird, we then summed the

267 observed number of overlaps by birds of each category over all watches and

268 determined the expected number of overlaps for birds of each category based on the

269 mean of 100 randomisation trials. Differences were tested with $\chi^{2}$ tests and plotted as

270 the percent of overlap events observed for each sex/status category combination that

271 was more or less than expected by chance.

272 Statistical analyses were conducted in R 3.0.3 (R Core Team 2014).

273

274 Ethical Note

275

$276 \quad$ Birds originating within the study area were colour-banded as nestlings;

277 immigrants were colour-banded by capturing birds at night in their roost cavities. In both 
278 cases, birds were returned to their territories as quickly as possible (usually within one

$279 \mathrm{hr}$ ) or at dawn in order to minimise disturbance. Observations were made from blinds

280 using spotting scopes so as to not alter natural patterns of provisioning behaviour.

281 Procedures were approved by the Animal Care and Use Committees of the University of 282 California, Berkeley (protocol R010-0412), Cornell University (protocol 2008-0185) and 283 Old Dominion University (protocol 12-001).

285 Results

All categories of birds, and all birds combined, clumped their feeding visits, in 288 most cases significantly (Figure 3). Generally this involved three or more visits within 5 289 min periods, the only exception being helper females, which most frequently fed only 290 twice within 5 min periods. Visits were also clumped when considering all visits 291 regardless of bird identify (Figure 3, 'all birds').

292 In contrast, all categories of birds exhibited fewer uninterrupted runs of two or 293 more visits in a row than expected by chance (Figure 4). Thus, birds most closely 294 exhibited pattern C1 in Table 1: visits were clumped in time for both individuals and 295 groups whereas runs of uninterrupted visits were less common than expected by 296 chance due to alternate feeding. Visitation bouts were both synchronised and 297 coordinated among group members.

298 These results are consistent with the hypothesis that birds are sensitive to the 299 provisioning behaviour of other individuals in the group and adjust their feeding 300 behaviour accordingly. We tested whether such behaviour was potentially directed 
301 toward other individuals of a particular sex or status, thereby serving a signalling

302 function, in two ways. First, focusing on absolute feeding rates, we found that birds in all

303 three categories fed less, not more, when other individuals of the same sex/status were

304 present, although the differences were significant for breeder males and only for helper

305 females in groups with a standardized composition (Table 2).

306 Second, we tested whether feeding was potentially directed toward other

307 individuals by quantifying patterns of overlap at the nest (Figure 5). When either a

308 breeder male or a breeder female was at or in the nest, the only category of bird that

309 overlapped more frequently than expected was other breeder females. There was no

310 tendency for helpers of either sex to overlap with breeders at the nest more frequently

311 than expected by chance. When helper males were at or in the nest, there was but a

312 marginally significant difference in the tendency for birds of different categories to

313 overlap with them, primarily due to a relatively high incidence of helper female, rather

314 than helper male, overlap. Differences in overlap by different categories of birds when

315 helper females were at or in the nest were not significant.

316

317 Discussion

Our analyses indicated that acorn woodpeckers both synchronise and coordinate

320 their feeding visits with other group members significantly more than expected by

321 chance. Such a pattern is consistent with the hypothesis that provisioning is a signal

322 used by at least some birds in the group to advertise either their quality or their

323 propensity to provision to other group members, as predicted by the social prestige and 
324 pay-to-stay hypotheses. Analyses of feeding rates by breeder males and overlap

325 between birds during provisioning visits, however, failed to support either of these

326 hypotheses. Three potential signalling functions were investigated.

327

328 Breeder Males Signalling Breeder Females (Social Prestige)

329

330

Two ways that provisioning behaviour might be used by breeder males to signal

331 their quality to breeder females is by increasing their actual feeding rate and by

332 increasing their perceived feeding rate by overlapping more frequently with breeder

333 females when the latter are at or in the nest. Controlling for other factors, including

334 composition of other sex/status categories, breeder males provisioned nestlings

335 significantly less, not more, frequently when they were in competition with other co-

336 breeders for the attention of breeder females (Table 2). In terms of overlap, the

337 incidence of breeder males overlapping with breeder females when the latter were at or

338 in the nest was not statistically different from chance (Figure 5). We are aware of no

339 prior tests of this hypothesis, which is only applicable to the small proportion of

340 cooperatively-breeding species, such as the acorn woodpecker, in which cobreeding

341 occurs regularly.

342

343 Helpers are Signalling to Other Helpers of the Same Sex (Social Prestige)

345 Helpers often form same-sex sibling coalitions that disperse together and

346 eventually cobreed. Thus, helpers that signal their quality by provisioning more 
347 frequently or by overlapping more with other helpers of the same sex could potentially

348 enhance their status or social prestige in a way that provides them with an advantage

349 later in life by signalling their quality to same-sex siblings. Our analyses, however,

350 indicated that helpers did not feed more frequently when living in groups with other

351 helpers of the same sex. Similarly, in terms of overlap, helpers exhibited little tendency

352 to overlap their provisioning with other helpers of the same sex more than expected by

353 chance. Although not specifically tested, no evidence for synchronous provisioning visits

354 by helpers was reported in the chestnut-crowned babbler, Pomatostomus ruficeps

355 (Nomano et al., 2015).

356

357 Helpers are Signalling to Breeders (Pay-to-Stay)

359 If provisioning by helpers is acting as a pay-to-stay mechanism, then helpers

360 would be expected to overlap more frequently with breeders so as to ensure that the

361 latter do not perceive them as being 'lazy' and evict them from the group. Our results

362 indicated that helper males did not overlap more frequently than expected with either

363 breeder males or breeder females, and that there was no significant difference overall in

364 overlap by helper females across the four sex/status categories. Similarly negative

365 results testing this hypothesis were found for bell miners in an experimental study in

366 which helpers failed to alter their provisioning behaviour when breeders (the

367 presumptive audience) were temporarily removed (McDonald et al., 2008), and in a

368 study of chestnut-crowned babblers, in which unrelated helpers were unresponsive, and 
369 exhibited no evidence of advertising their provisioning behaviour, to dominant males

370 (Nomano et al., 2015).

372 Provisioning Behaviour as a Signal

$374 \quad$ Our results fail to support the hypothesis that provisioning functions as a signal to 375 other group members in any of the ways that we considered plausible, despite the 376 emergence of detectable patterns in the feeding bouts of both individual birds and 377 groups as a whole indicating that birds are sensitive to the provisioning activities of 378 others in the group. Birds tended to clump their feeding visits, a finding that suggests

379 either that birds are foraging in some coordinated manner or that they are paying 380 attention to the provisioning activities of other birds so as synchronise their feeding 381 visits. This pattern runs counter to the hypothesis that birds are attempting to feed 382 young in an efficient manner that is likely to maximise digestive efficiency (Lepczy, 383 Caviedes-Vidal, \& Karasov, 1998; Karasov \& Wright, 2002). Concomitantly, runs of 384 uninterrupted visits were less common than expected, suggesting that birds alternate 385 their feeding visits, a pattern that has been detected in the socially monogamous great 386 tit where it was proposed to be a mechanism of negotiation between parents reducing 387 parental conflict over offspring care (Johnstone et al., 2014), and was found to be 388 associated with increased reproductive success in the cooperatively-breeding long389 tailed tit, possibly due to reduced activity around the nest (Bebbington \& Hatchwell, 390 2016). 
Nonetheless, neither synchronisation nor alternation resulted in one category of

392 birds overlapping significantly more at the nest than expected with another category of

393 birds in any of the ways we predicted if provisioning were a signal that enhanced

394 fitness. Similarly, neither breeder males nor helpers fed more frequently when in groups

395 with other birds of the same sex/status category. Thus, although birds are apparently

396 sensitive to what other group members are doing when they provision at nests, they do

397 so indiscriminately, contrary to the predictions of either the social prestige or pay-to-stay

398 hypotheses, both of which are predicated on the idea that provisioning is an opportunity

399 for birds to advertise their quality or helpfulness to specific group members (Wright \&

400 McDonald, 2016).

401 These results add to prior studies that have failed to support the hypothesis that

402 provisioning behaviour functions as a signal in cooperative breeders, including the bell

403 miner (Wright, 1997; McDonald et al., 2008; Wright \& McDonald, 2016), and several

404 investigations of 'false-feeding' behaviour (Wright, 1997; Canestrari, Marcos, \&

405 Baglione, 2004; Clutton-Brock, Russell, Sharpe, \& Jordan, 2005; McDonald, Kazem, \&

406 Wright, 2007), which was proposed as a deceptive strategy employed by helpers to

407 enhance their social prestige at minimal cost in white-winged choughs, Corcorax

408 melanorhamphos (Boland, Heinsohn, \& Cockburn 1997). The only exception to this

409 generalisation is the cooperatively-breeding fish Neolamprologus pulcher, in which pay-

410 to-stay has been carefully examined both empirically and experimentally and shown to

411 be key to helping behaviour (Taborsky, 2016). It is worth noting, however, that

412 Neolamprologus differs from the cooperative breeding birds discussed here in that 
413 'helpers' are generally aspiring breeders rather than related offspring (Koenig,

414 Dickinson, \& Emlen 2016).

415 As mentioned above, there are other potential benefits to birds altering their

416 behaviour in response to the provisioning of others and adjusting their own behaviour

417 accordingly beyond the obvious adjustments that take place in feeding rates due to the

418 loss, or addition, or provisioning by other group members (Liebl et al., 2016). These

419 include reducing predation risk by reducing the number of temporally separate nest

420 visits (Raihani et al., 2010; Bebbington \& Hatchwell, 2016) and reduced parental conflict

421 over nestling care (Johnstone et al., 2014). Thus the coordinated provisioning behaviour

422 found here may serve one of these other selective functions. It is even possible that

423 provisioning behaviour acts as a signal to conspecifics in some way other than those

424 considered here. In our case, however, acorn woodpeckers neither display nor regularly

425 vocalise during feeding visits, and thus what such a covert signal might consist of is not

426 obvious. Although one of the activities of many species that is easiest to observe and

427 quantify, provisioning behavior appears to be used as a signal that is acted upon by

428 few, if any, cooperatively breeding birds.

429

\section{Acknowledgments}

We thank the many assistants who conducted the nest watches included in this

433 study, students from Old Dominion University Learn and Earn Advantage Program for

434 digitising historic nestwatches, Annie Sabo for organising the data, and particularly

435 Doug Schaefer, who wrote the Excel program used to computerise the nest watch data. 
436 We gratefully acknowledge the Museum of Vertebrate Zoology (UC Berkeley) and

437 Hastings Reservation for logistical support, the National Science Foundation for

438 financial support (most recently through grants IOS-1455881 and IOS-1455900), and

439 the reviewers for their comments.

440

\section{References}

442

443 Bebbington, K., \& Hatchwell, B. J. (2016). Coordinated parental provisioning is related

444 to feeding rate and reproductive success in a songbird. Behavioral Ecology, 27, $445 \quad 652-659$.

446 Boland, C. R. J., Heinsohn, R., \& Cockburn, A. (1997). Deception by helpers in 447 cooperatively breeding white-winged choughs and its experimental manipulation. $448 \quad$ Behavioral Ecology and Sociobiology, 41, 251-256.

449 Budden, A. E., \& Wright, J. (2007). Effects of feeding frequency on nestling begging and 450 digestion. Ibis, 150, 234-241.

451 Canestrari, D., Marcos, J. M., \& Baglione, V. (2004). False feeding at the nests of 452 carrion crows Corvus corone corone. Behavioral Ecology and Sociobiology, 55, $453 \quad 477-483$.

454 Canestrari, D., Marcos, J. M., \& Baglione, V. (2007). Costs of chick provisioning in 455 cooperatively breeding crows: an experimental study. Animal Behaviour, 73, 349$456 \quad 357$.

457 Clutton-Brock, T. H., Russell, A. F., Sharpe, L. L., \& Jordan, N. R. (2005). 'False 458 feeding' and aggression in meerkat societies. Animal Behaviour, 69, 1273-1284. 
459 Doutrelant, C., \& Covas, R. (2007). Helping has signalling characteristics in a $460 \quad$ cooperatively breeding bird. Animal Behaviour, 74, 739-747.

461 Gaston, A. J. (1978). The evolution of group territorial behavior and cooperative 462 breeding. American Naturalist, 112, 1091-1100.

463 Harrison, F., Barta, Z., Cuthill, I., \& Székely, T. (2009). How is sexual conflict over 464 parental care resolved? A meta-analysis. Journal of Evolutionary Biology, 22, $465 \quad 1800-1812$.

466 Hatchwell, B. J. (1999). Investment strategies of breeders in avian cooperative breeding $467 \quad$ systems. American Naturalist, 154, 205-219.

468 Hatchwell, B. J. (2016). Long-tailed tits: ecological causes and fitness consequences of 469 redirected helping. In W. D. Koenig \& J. L. Dickinson (Eds.), Cooperative $470 \quad$ breeding in vertebrates: studies of ecology, evolution, and behavior (pp. 39-57). $471 \quad$ Cambridge, UK: Cambridge University Press.

472 Haydock, J., \& Koenig, W. D. (2002). Reproductive skew in the polygynandrous acorn $473 \quad$ woodpecker. Proceedings of the National Academy of Sciences (USA), 99, 7178474 7183.

475 Haydock, J., \& Koenig, W. D. (2003). Patterns of reproductive skew in the 476 polygynandrous acorn woodpecker. American Naturalist, 162, 277-289.

477 Hinde, C. A., \& Kilner, R. M. (2007). Negotiations within the family over the supply of 478 parental care. Proceedings of the Royal Society of London, Series B, 274, 53-60.

479 Johnstone, R. A., \& Hinde, C. A. (2006). Negotiation over offspring care-how should 480 parents respond to each other's efforts? Behavioral Ecology, 17, 818-827. 
481 Johnstone, R. A., Manica, A., Fayet, A. L., Stoddard, M. C., Rodriguez-Gironés, M. A., \& $482 \quad$ Hinde, C. A. (2014). Reciprocity and conditional cooperation between great tit 483 parents. Behavioral Ecology, 25, 216-222.

484 Karasov, W. H., \& Wright, J. (2002). Nestling digestive physiology and begging. In J. 485 Wright \& M. L. Leonard (Eds.), The evolution of begging: competition, 486 cooperation and communication (pp. 199-219). New York: Kluwer Academic $487 \quad$ Press.

488 Kilner, R. M., \& Johnstone, R. A. (1997). Begging the question: are offspring solicitation 489 behaviours signals of need? Trends in Ecology and Evolution, 12, 11-15.

490 Koenig, W. D., Dickinson, J. L., \& Emlen, S. T. (2016). Synthesis: cooperative breeding 491 in the twenty-first century. In W. D. Koenig \& J. L. Dickinson (Eds.), Cooperative $492 \quad$ breeding in vertebrates: studies of ecology, evolution, and behavior ( $\mathrm{pp}$. 353493 374). Cambridge, UK: Cambridge University Press.

494 Koenig, W. D., \& Mumme, R. L. (1987). Population ecology of the cooperatively 495 breeding acorn woodpecker. Princeton, NJ: Princeton University Press.

496 Koenig, W. D., Mumme, R. L., \& Pitelka, F. A. (1984). The breeding system of the acorn 497 woodpecker in central coastal California. Zietschrift für Tierpsychologie, 65, 289498 308.

499 Koenig, W. D., \& Walters, E. L. (2011). Age-related provisioning behaviour in the $500 \quad$ cooperatively breeding acorn woodpecker: testing the skills and the pay-to-stay $501 \quad$ hypotheses. Animal Behaviour, 82, 437-444. 
502 Koenig, W. D., \& Walters, E. L. (2012). Brooding, provisioning, and compensatory care 503 in the cooperatively breeding acorn woodpecker. Behavioral Ecology, 23, 181$504 \quad 190$.

505 Koenig, W. D., Walters, E. L., \& Haydock, J. (2016). Acorn woodpeckers: helping at the 506 nest, polygynandry, and dependence on a variable acorn crop. In W. D. Koenig \&

507

508 509

510 Kokko, H., Johnstone, R. A., \& Wright, J. (2002). The evolution of parental and alloparental effort in cooperatively breeding groups: when should helpers pay to

513 Leonard, M. L., \& Horn, A. G. (2001). Begging calls and parental feeding decisions in 514 tree swallows (Tachycineta bicolor). Behavioral Ecology and Sociobiology, 49, $515 \quad 170-175$

516 Lepczyk, C. A., Caviedes-Vidal, E., \& Karasov, W. H. (1998). Digestive responses 517 during food restriction and realimentation in nestling house sparrows (Passer 518 domesticus). Physiological Zoology, 71, 561-573.

519 Liebl, A. L., Browning, L. E., \& Russell, A. F. (2016). Manipulating carer number versus 520 brood size: complementary but not equivalent ways of quantifying carer effects $521 \quad$ on offspring. Behavioral Ecology, doi: 10.1093/beheco/arw038

522 McDonald, P. G., Kazem, A. J. N., \& Wright, J. (2007). A critical analysis of 'false523 feeding' behavior in a cooperatively breeding bird: disturbance effects, satiated 524 nestlings or deception? Behavioral Ecology and Sociobiology, 61, 1623-1635. 
525 McDonald, P. G., Kazem, A. J. N., Clarke, M. F., \& Wright, J. (2008). Helping as a

526 signal: does removal of potential audiences alter helper behavior in the bell 527 miner? Behavioral Ecology, 19, 1047-1055.

528 Meade, J., Nam, K.-B., Beckerman, A. P., \& Hatchwell, B. J. (2010). Consequences of 529 'load-lightening' for future indirect fitness gains by helpers in a cooperatively 530 breeding bird. Journal of Animal Ecology, 79, 529-537.

531 Mitchell, J. S. (2003). Social correlates of reproductive success in false clown 532 anemonefish: subordinate group members do not pay-to-stay. Evolutionary $533 \quad$ Ecology Research, 5, 89-104.

534 Mulder, R. A., \& Langmore, N. E. (1993). Dominant males punish helpers for temporary 535 defection in superb fairy-wrens. Animal Behaviour, 45, 830-833.

536 Nomano, F. Y., Browning, L. E., Rollins, L. A., Nakagawa, S., Griffith, S. C., \& Russell, 537 A. F. (2013). Feeding nestlings does not function as a signal of social prestige in 538 cooperatively breeding chestnut-crowned babblers. Animal Behaviour, 86, 277539289.

540 Nomano, F. Y., Browning, L. E., Savage, J. L., Rollins, L. A., Griffith, S. C., \& Russell, A. 541 F. (2015). Unrelated helpers neither signal contributions nor suffer retribution in 542 chestnut-crowned babblers. Behavioral Ecology, 26, 986-995.

543 Pinheiro, J., Bates, D., DebRoy, S., Sarkar, D. and R Core Team (2013). nlme: linear 544 and nonlinear mixed effects models. R package version 3.1-113, http://CRAN.R545 project.org/package=nlme. 
546 R Core Team (2014). R: A language and environment for statistical computing Version

547 3.0.3). Vienna, Austria: R Foundation for Statistical Computing. http://www.R$548 \quad$ project.org/.

549 Raihani, N. J., Nelson-Flower, M. J., Moyes, K., Browning, L. E., \& Ridley, A. R. (2010). $550 \quad$ Synchronous provisioning increases brood survival in cooperatively breeding 551 pied babblers. Journal of Animal Ecology, 79, 44-52.

552 Sæther, B.-E. (1994). Food provisioning in relation to reproductive strategy in altricial 553 birds: a comparison of two hypotheses. Evolution, 48, 1397-1406.

554 Santema, P., \& Clutton-Brock, T. (2012). Dominant female meerkats do not use 555 aggression to elevate work rates of helpers in response to increased brood 556 demand. Animal Behaviour, 83, 827-832.

557 Taborsky, M. (2016). Cichlid fishes: a model for the integrative study of social behavior.

558 In W. D. Koenig \& J. L. Dickinson (Eds.), Cooperative breeding in vertebrates:

559 studies of ecology, evolution, and behavior (pp. 272-293). Cambridge, UK:

$560 \quad$ Cambridge University Press.

561 Wright, J. (1997). Helping-at-the-nest in Arabian babblers: signalling social status or $562 \quad$ sensible investment in chicks? Animal Behaviour, 54, 1439-1448.

563 Wright, J., \& McDonald, P. G. (2016). Bell miners: kin-selected helping decisions. In W.

564 D. Koenig \& J. L. Dickinson (Eds.), Cooperative breeding in vertebrates: studies 565 of ecology, evolution, and behavior (pp. 165-180). Cambridge, UK: Cambridge $566 \quad$ University Press. 
567 Zahavi, A. (1977). Reliability in communication systems and the evolution of altruism. In

568 B. Stonehouse \& C. M. Perrins (Eds.), Evolutionary ecology (pp. 253-259).

$569 \quad$ London: Macmillan.

570 Zahavi, A. (1990). Arabian babblers: the quest for social status in a cooperative

571 breeder. In P. B. Stacey \& W. D. Koenig (Eds.). Cooperative breeding in birds:

572 long term studies of ecology and behavior (pp. 103-130). Cambridge, UK:

$573 \quad$ Cambridge University Press.

574 Zahavi, A. (1995). Altruism as a handicap—the limitations of kin selection and

575 reciprocity. Journal of Avian Biology, 26, 1-3. 


\section{Table 1}

Potential outcomes of the analyses and their interpretation

\begin{tabular}{lccc}
\hline Clumping pattern & $\begin{array}{c}\text { A) Runs of uninterrupted } \\
\text { visits more common than } \\
\text { expected } \\
\text { (time-sharing) }\end{array}$ & B) Runs random & $\begin{array}{c}\text { C) Runs of uninterrupted } \\
\text { visits less common than } \\
\text { expected }\end{array}$ \\
\hline $\begin{array}{l}\text { 1) Visits are clumped in } \\
\text { time for both individuals } \\
\text { and groups }\end{array}$ & $\begin{array}{c}\text { Feeding bouts } \\
\text { synchronised and } \\
\text { coordinated } \\
\text { (alternate feeding) }\end{array}$ & $\begin{array}{c}\text { Feeding bouts synchronised } \\
\text { but not coordinated }\end{array}$ & $\begin{array}{c}\text { Feeding bouts } \\
\text { synchronised and } \\
\text { coordinated }\end{array}$ \\
$\begin{array}{l}\text { 2) Visits are clumped in } \\
\text { time for groups but not } \\
\text { individuals }\end{array}$ & - & $\begin{array}{c}\text { Feeding bouts synchronised } \\
\text { but not coordinated }\end{array}$ & $\begin{array}{c}\text { Feeding bouts } \\
\text { synchronised and } \\
\text { coordinated }\end{array}$ \\
$\begin{array}{l}\text { 3) Visits are not clumped } \\
\text { in time for either } \\
\text { individuals or groups }\end{array}$ & $\begin{array}{c}\text { Feeding bouts coordinated } \\
\text { but not synchronised }\end{array}$ & $\begin{array}{c}\text { Feeding bouts neither } \\
\text { synchronised nor } \\
\text { coordinated }\end{array}$ & $\begin{array}{c}\text { Feeding bouts coordinated } \\
\text { but not synchronised }\end{array}$ \\
\hline
\end{tabular}

Box 2A was considered an incompatible outcome. 


\section{Table 2}

Results of mixed-effects models testing whether breeder males, helper males, or helper females adjust their feeding rate depending on whether they are in the group (and thus competing) with other birds of the same category

\begin{tabular}{lcccc}
\hline Variable & $\begin{array}{c}\text { Effect size } \\
(\text { mean } \pm \text { SE })\end{array}$ & df & t-value & $P$-value \\
\hline $\begin{array}{l}\text { Analyses including all four sex/status categories } \\
\text { Breeder males }\end{array}$ & $-0.36 \pm 0.05$ & 926 & -6.83 & $<0.001$ \\
Helper males & $-0.02 \pm 0.04$ & 2463 & -0.49 & 0.62 \\
$\begin{array}{l}\text { Helper females } \\
\text { Analyses of groups with a standardized }\end{array}$ & $-0.08 \pm 0.09$ & 376 & -0.87 & 0.38 \\
$\begin{array}{l}\text { Bomposition } \\
\text { Breeding males }\end{array}$ & $-0.50 \pm 0.11$ & 153 & -4.47 & $<0.001$ \\
Helper males & $-0.15 \pm 0.12$ & 34 & -1.24 & 0.22 \\
Helper females & $-0.87 \pm 0.34$ & 11 & -2.53 & 0.03 \\
\hline
\end{tabular}

Analyses controlled for group composition by including the number of birds in other sex/status categories as explanatory factors (top half) or by limiting analysis to groups with a standardized composition. The latter were: one breeder female and no helpers (for breeder males); one breeder of both sexes and no helpers of the opposite sex (for helper males and helper females). Although not listed, each of the six models included the number of young in the nest, the number of young banded, maximum temperature the day of the watch, time of day, and age of the nestlings (both linear and quadratic terms) as explanatory factors along with the number of breeder males or number of helpers of the listed sex. All analyses included the nested random factor 'bird ID' within 'nest' within 'group'. 


\section{Figure legends}

Figure 1. A visualisation of the potential patterns of clumping and runs of uninterrupted feeding visits by individuals including whether the pattern is considered to exhibit synchronisation or coordination among individuals. In each case, time moves horizontally and a vertical line represents a feeding visit by one of three individuals or all group members combined.

Figure 2. Distribution of feeding intervals for the four categories of birds. Values are binned into 5-min intervals, with the $y$-axis being the proportion of feeding intervals by individual birds that occurred within that time interval.

Figure 3. Clumping of feeding visits (number of feeding visits within 5 min of a feeding visit occurring at least 5 min after any other visit) by individual birds (breeder males, breeder females, helper males, and helper females) and by all birds combined within groups. Plotted is the percent difference from that expected by chance based on visits occurring at random during the watch (see text). Differences are tested with $\chi^{2}$ tests with 3 df; $p$-values are listed. $\chi^{2}$ values (category; $N$ visits): 6.3 (breeder males; 14,375), 6.2 (breeder females; 12,433), 44.2 (helper males; 5,159), 15.1 (helper females; 3,867), and 202.7 (all birds combined; 17,816).

Figure 4. Runs of uninterrupted feeding visits by individual birds (breeder males, breeder females, helper males, and helper females). Plotted is the percent difference from that expected by chance based on randomisation tests (see text). Differences are tested with $\chi^{2}$ tests with $3 \mathrm{df} ; p$-values are listed. $\chi^{2}$ values (category; $N$ visits):178.7 
(breeder males; 17,246), 214.6 (breeder females; 15,704), 59.0 (helper males; 5,549), and 48.9 (helper females; 4,158).

Figure 5. Overlap in visits during provisioning visits by individual birds of the four sex/status categories. Plotted is the percent difference from that expected by chance for the proportion of times birds of the given category $(\mathrm{BM}=$ breeder males; $\mathrm{BF}=$ breeder females; $\mathrm{HM}=$ helper males; $\mathrm{HF}=$ helper females) arrived at the nest and overlapped with a bird already at or in the nest of the category listed. The expected values are generated from randomisation trials based on the number of visits by birds in each category during watches (see text). Differences are tested with $\chi^{2}$ tests with $3 \mathrm{df} ; p$ values are listed. $\chi^{2}$ values (category; $N$ overlap events): 743.7 (breeder males; 2,154 ), 40.5 (breeder females; 1,594), 8.4 (helper males; 709), and 4.3 (helper females; 595). Note that the $y$-axis scales are not the same across the four graphs. 
Fig. 1

\section{A) Runs more common than expected (time-sharing)}

Clumping pattern

\begin{tabular}{|c|c|c|}
\hline & 1) Individuals and groups & 3) Neither individuals nor groups \\
\hline Bird 1 & $\|\quad\| \|$ & ||$|\quad|$ \\
\hline Bird 2 & \|\| & 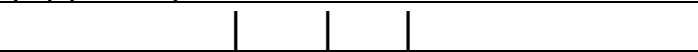 \\
\hline Bird 3 & \|\| & 1 \\
\hline Group & $|\||||||||$ & || $\mid$ \\
\hline Synchronised? & Yes & No \\
\hline Coordinated? & Yes & Yes \\
\hline
\end{tabular}

\section{B) Runs random}

Clumping pattern

\begin{tabular}{|c|c|c|c|}
\hline & $\begin{array}{c}\text { 1) Individuals and } \\
\text { groups }\end{array}$ & $\begin{array}{l}\text { 2) Groups but not } \\
\text { individuals }\end{array}$ & 3) Neither individuals nor groups \\
\hline Bird 1 & $\||| \quad\| \|$ & & 1 \\
\hline Bird 2 & || & 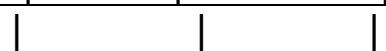 & 11 \\
\hline Bird 3 & | || & 1 & 1 \\
\hline Group & $\||| \mid$ & $\frac{1}{\|\|}$ & $\| 1 \mid$ \\
\hline Synchronised? & Yes & Yes & No \\
\hline Coordinated? & No & No & No \\
\hline
\end{tabular}

C) Runs less common than expected (alternate feeding)

Clumping pattern

\begin{tabular}{|c|c|c|c|}
\hline & $\begin{array}{l}\text { 1) Individuals and } \\
\text { groups }\end{array}$ & $\begin{array}{l}\text { 2) Groups but not } \\
\text { individuals }\end{array}$ & 3) Neither individuals nor groups \\
\hline Bird 1 & || $\mid$ & 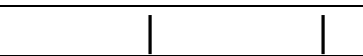 & 1 \\
\hline Bird 2 & || & | & | \\
\hline Bird 3 & $\mid$ & 1 & | \\
\hline Group & |||||| & $\|$ & 1 \\
\hline Synchronised? & Yes & Yes & No \\
\hline Coordinated? & Yes & Yes & Yes \\
\hline
\end{tabular}


Fig. 2
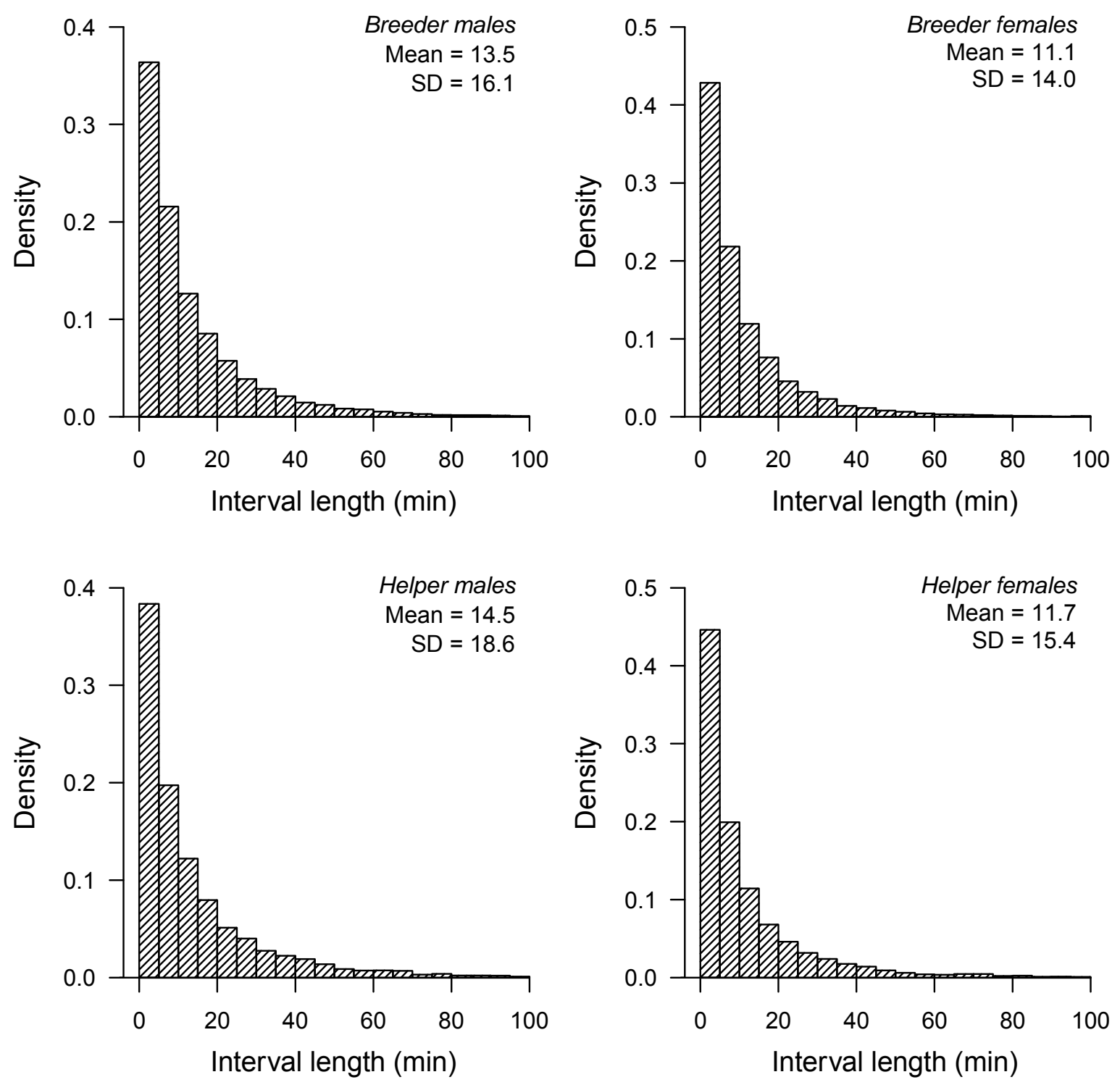
Fig. 3
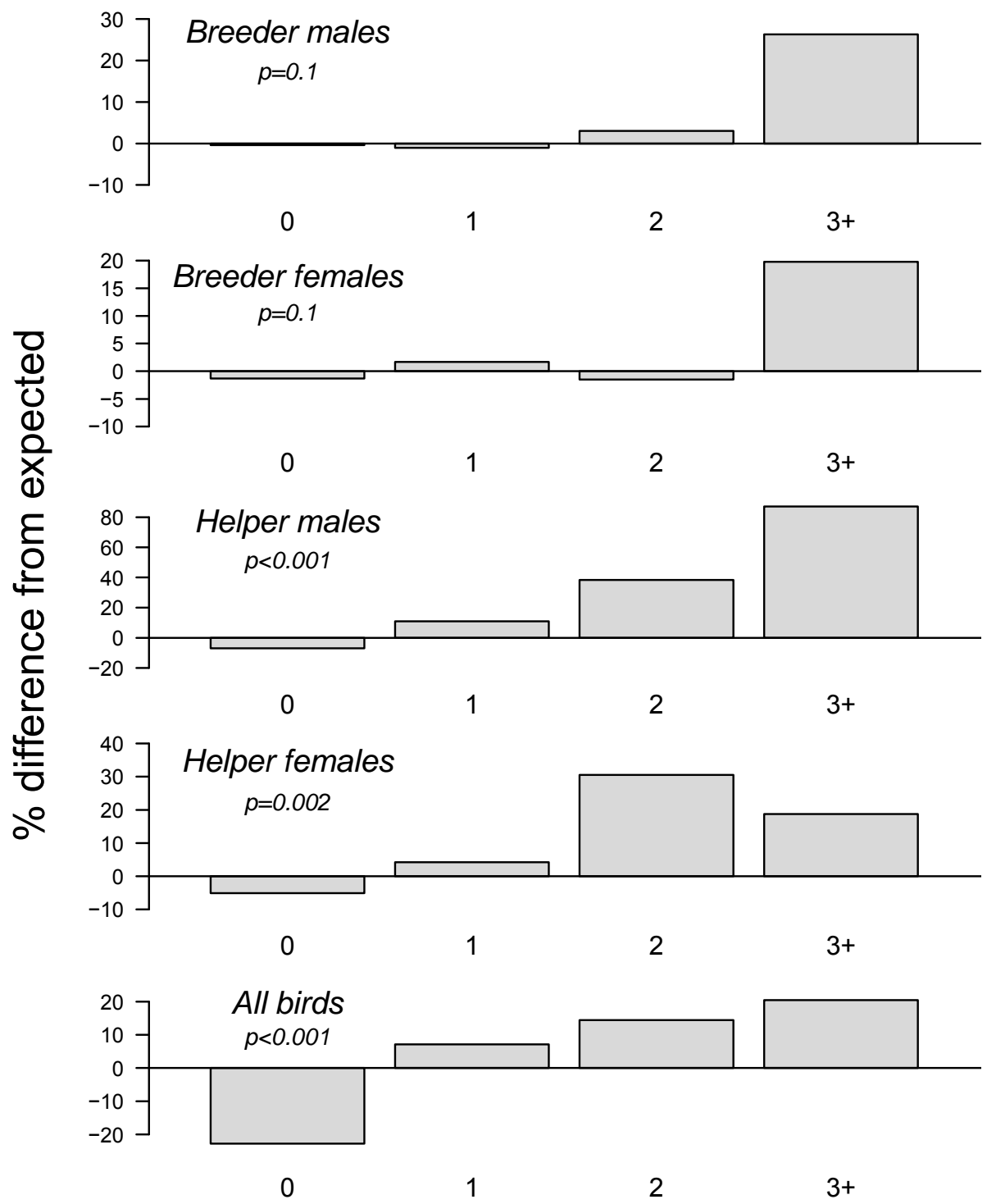

Feeds within 5 min 
Fig. 4
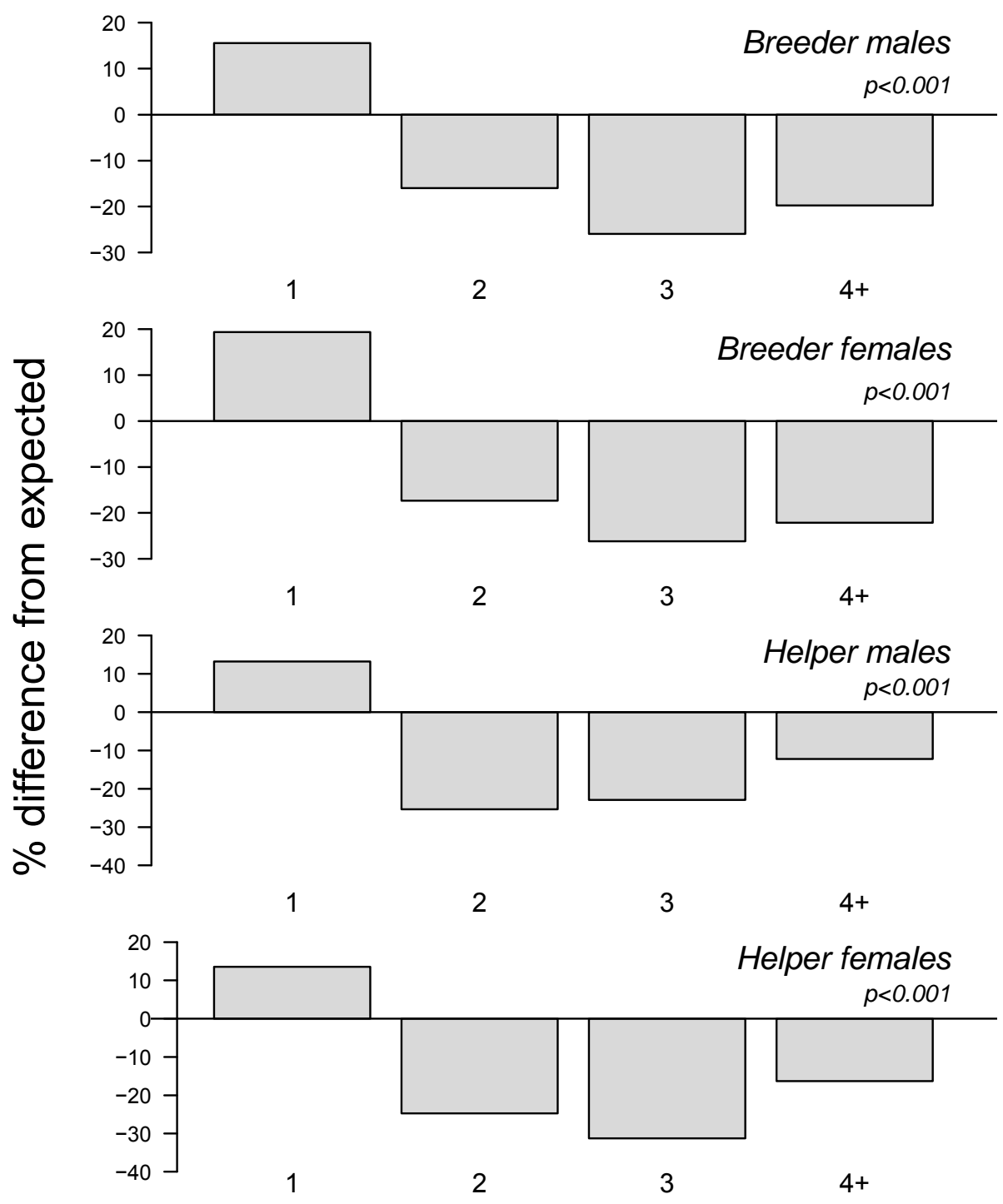

Feeds within $5 \mathrm{~min}$ 
Fig. 5

Bird in nest:
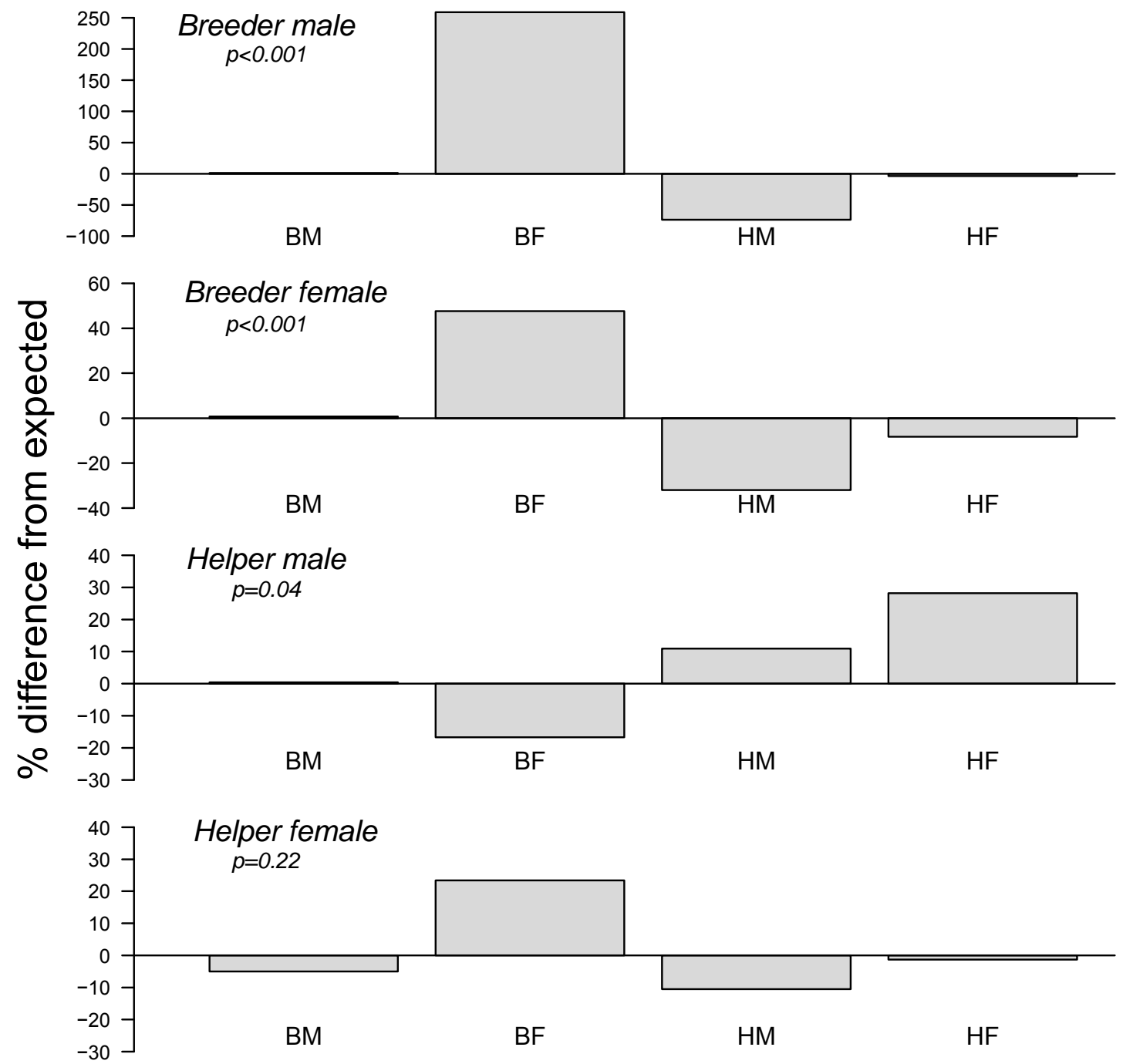

Bird arriving 